ORIGINAL PAPER

\title{
Hydrocephalus and shunts:
}

\section{a comparative flow-pressure study}

\author{
Angelo Luiz Maset ${ }^{1}$. Matheus Fernando Manzolli Ballestero ${ }^{2}$, Dionei Freitas de Moraes ${ }^{1}$
}

Received: 04 August 2020 / Published: 30 January 2021

\begin{abstract}
Introduction: Differential Pressure Shunts (DPS) for hydrocephalus work through a pressure differential between the proximal and the distal inlet. Neurosurgeon's reference is extra-low, low, medium, normal or high-pressure valves, symbolizing the shunt's resistance against the downstream flow. The Brazilian manufacturing process for all shunts is regulated by ISO 7195 version 2006, revised in 2016, and it allows a lot of flexibility in the determination of shunt resistance and flow characteristics.

Methods: This article compares the pressure-flow characteristics of some hydrocephalus shunts available in Brazil based on their information brochures

Results: Six shunt information brochures were compared regarding to CSF flow-control manufacturing graphs and/or pressure work range tables. Based on the data obtained of each valve, authors propose and introduce a comparative graphic table that can be helpful if used as a guide to the neurosurgeon when one considers either a first time shunt implantation or a shunt revision

Conclusion: There is no standardization regarding the pressure which defines the different models of shunts available in Brazil and neurosurgeon must be aware when choosing a specific shunt and even more when, in a shunt review, choose another manufacturer.
\end{abstract}

Key words: Hydrocephalus. Ventriculoperitoneal shunt. Differential pressure shunt. Shunt pressure. Bench test

\footnotetext{
${ }^{1}$ Department of Neurosurgery, FUNFARME, São José do Rio Preto, SP, Brazil.

2 Department of Medicine, Federal University of São Carlos, São Carlos, Brazil
}

To whom correspondence should be addressed: Angelo Luiz Maset, MD, PhD [E-mail: amaset@me.com]

Journal homepage: www.sbnped.com.br

\section{Introduction}

All hydrocephalus systems work through a pressure differential (DP) between the proximal (ventricular) and the distal catheter (most commonly the peritoneal)[1,2]. There are criteria to manufacture a shunt dictated by the International Standard Organization (ISO) rule 7197, revised edition of 2016, called "Neurosurgical implants - Sterile, single-use hydrocephalus shunts and components" [3]. It specifies the methodology for the manufacturing process, which is basically divided in 6 steps: (1) Leak resistance. (2) Reflux Resistance. (3) Pressure versus flow characteristics. (4) Long-term stability. (5) Resistance to high pressures. (6) Resistance to rupture.

ISO 7197 mentions that different resources can be employed for the implementation of flow and pressure collection systems, provided that they meet the requirements of the standard and provide better technical conditions in carrying out the activities. Several researchers utilize hydrodynamic bench test to evaluate the performance of the neurological valves and components present in shunts. To perform pressure-flow tests and evaluate the valves, Allin et al. [7] and Czosnyka et al. [8], employed a standard bench test containing pressure transducers, a water reservoir at a constant level, an infusion pump, a pulse generator and an electronic balance, with an additional apparatus that allowed the testing of shunts in a pressurized environment.

One must remember that besides hydrocephalus, shunt overdrainage syndrome (SOS) represents a challenge for neurosurgeons, in part due to the lack of agreement or uniformity concerning the entity. It's an incompletely understood condition characterized by the appearance of severe headache which interferes with activities of daily living, in patients with a CSF shunt valve and normal or smaller than normal ventricles[8]. Although there are no consensus regarding to its definition, it is consensus that the implanted shunt is the protagonist of the this complication been directly related to their manufactory characteristics[9].

In summary, the current ISO 7197 version allows variable ways of shunt resistance classification, which 


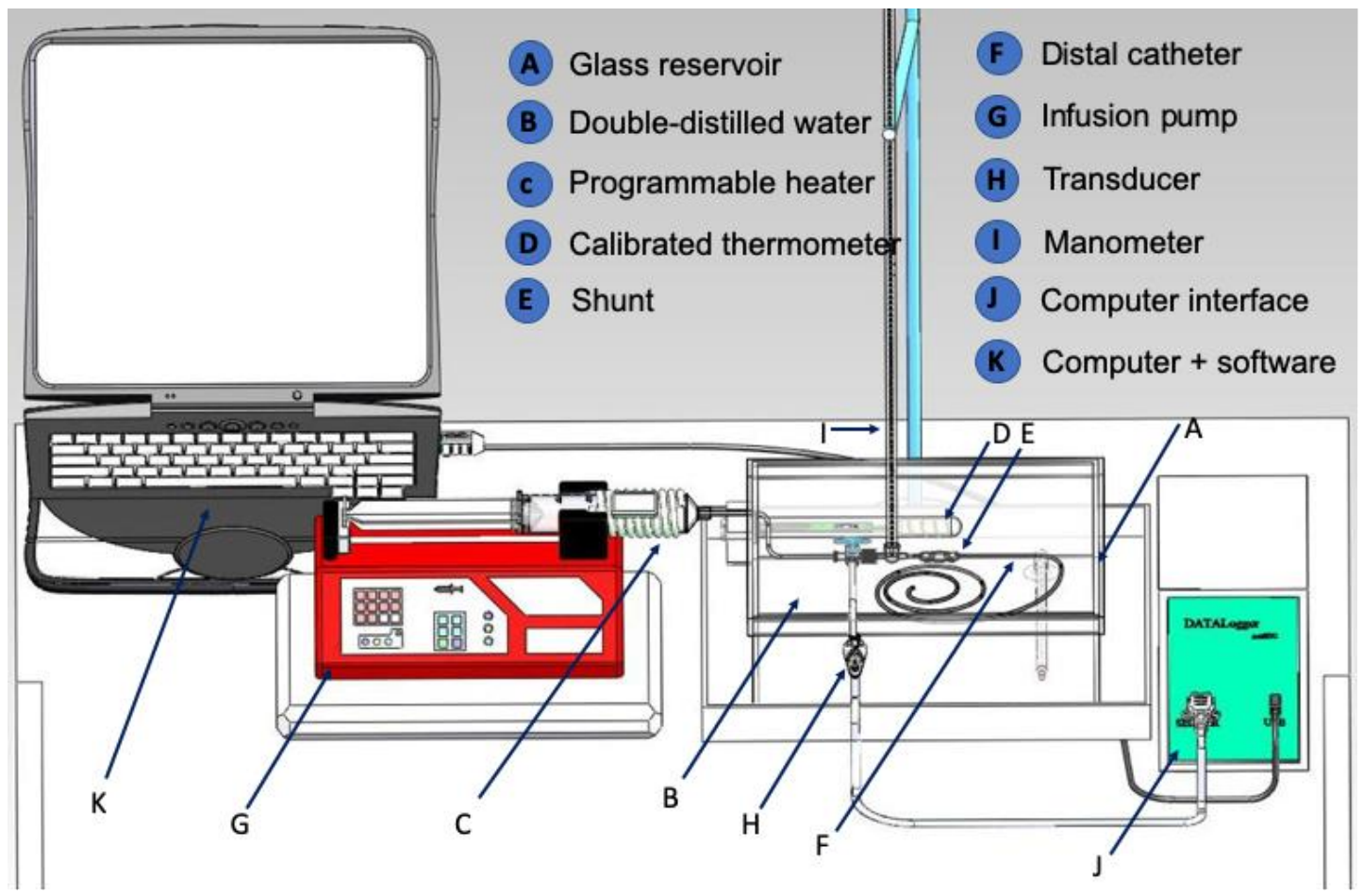

Figure 1 - Bench test for pressure-flow shunt graph characterization.

causes a lot of misunderstanding in neurosurgical practice. The aim of this paper was to compare the nominal pressure determination of each manufacturer supplier in Brazil according to the specifications available in the Instructions for user brochure supplied with the shunt, and to propose a guideline to consult either a first-time shunt implantation or a shunt revision.

\section{Material and Methods}

Shunt manufacturers determine the pressure-flow characteristic through a certified bench test, as described by Allin et al.[7] and Czosnyka et al. [8]. Briefly (Figure 1), the apparatus for testing the valves consists of a glass reservoir (a) containing doubledistilled water (b) with a temperature of $37 \pm 5^{\circ} \mathrm{C}$ Celsius by the actuation of a programmable heater (c) and verified with the aid of a calibrated thermometer (d). To obtain the variables (pressure and flow) obtained by the test, a programmable infusion pump (g) is used to push distilled water present in a syringe (c), which ultimately is connected to the shunt (e). Just before the shunt connector there is a connection to a manometer (i). At first, the fluid pumped through the tubing set will not open the valve, and the fluid will rise through the manometer. Once the shunt opening pressure is reached, fluid flows through the shunt and the water column stabilizes; that pressure is the shunt resistance, simulating the patient in a horizontal position. In this setting, the distal catheter ( $f$ ) remains within the reservoir (b) at the same level of the shunt. Pressure is continuously measured by a transducer (h) connected just before the manometer (i), digitalized by a datalogger (j) and sent to a computer (k) with a software which displays continually whatever data is desired [1,2]. lacerated vessel.

For the test of each valve, flow rates of $50,40,30$, 20,10 and $5 \mathrm{ml} / \mathrm{h}$ are programmed in the system for a period of five minutes for each flow, to guarantee the stability of the system. The values obtained must be within the upper limit of control (LSC) and the lower limit of control (LIC) determined for the valve to be approved, otherwise it fails. Once the above tests are done (pulsatile flow at fixed pressure), the average is taken from each input flow.

Based on those tests performed by manufacturers, the author collected data from each Information booklet available with the shunt and developed a logical and intuitive comparative pressure table among more common shunts available in Brazil.

\section{Results}

Table 1 summarizes the data available at shunt information brochures.

Medtronic ${ }^{\circledR}$ CSF flow-control ${ }^{\circledR}$ note says: "Levels depicted are median values. All valves perform within $+/-25 \mathrm{mmH} 2 \mathrm{O}$ tolerance at $0 \mathrm{~cm}$ Hydrostatic Pressure (HP), and the very low-pressure valves perform within $+/-10 \mathrm{mmH} 2 \mathrm{O}$ at $5 \mathrm{ml} / \mathrm{h}$ and $+/-20 \mathrm{mmH} 2 \mathrm{O}$ at $50 \mathrm{ml} / \mathrm{h}$. Each valve is tested at time of manufacture". So, a medium pressure valve varies from an average of 90 +/- $25 \mathrm{mmH} 2 \mathrm{O}$, that is, it may go from 65 up to 115 $\mathrm{mmH} 2 \mathrm{O}$. 
Table 1 - Shunt information extracted from brochure data available with shunts and manufacture website

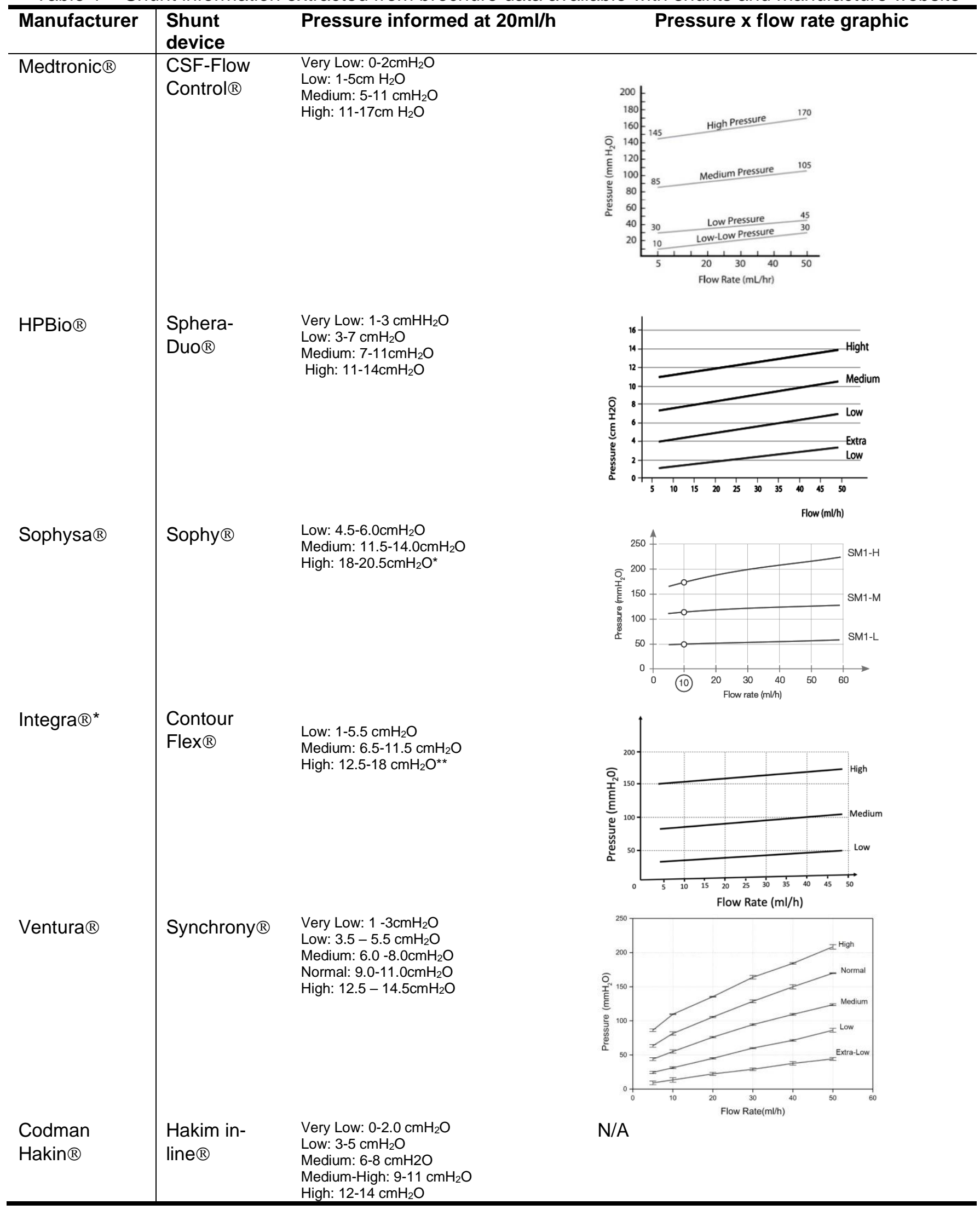

* Values to $20 \mathrm{ml} / \mathrm{h}$ (graphs emphasizes $10 \mathrm{ml} / \mathrm{h}$ )

${ }^{* *}$ Adapted from original graph 
$\mathrm{HP} \mathrm{BIO}{ }^{\circledR}$ note says "the graph presents average values. Consider a tolerance range of $+/-1,5 \mathrm{~cm} \mathrm{H} 2 \mathrm{O}$. Thus, a medium pressure valve may vary from 70 to $110+/-15 \mathrm{~mm} \mathrm{H} 2 \mathrm{O}$; that is, it may go from 55 up to $125 \mathrm{mmH} 2 \mathrm{O}$.

Sophy ${ }^{\circledR}$ (Sophysa ${ }^{\circledR}$ ) graph note says "Table of mean values at $10 \mathrm{ml} / \mathrm{h}$ for each position setting of the Sophy mini valve, and corresponding values at 20 $\mathrm{ml} / \mathrm{h}$ ". For the equivalency graph, it will be used an equivalent flow of $20 \mathrm{ml}$ as others. The tolerance is $10 /+15 \mathrm{mmH} 2 \mathrm{O}$ on median pressures; Thus, a medium pressure valve is $125 \mathrm{mmH} 2 \mathrm{O}$; that is, it may go from 115 up to $140 \mathrm{mmH} 2 \mathrm{O}$.

Integra ${ }^{\circledR}$ (Contour Flex ${ }^{\circledR}$ ) does not define a median pressure, but a range of pressure for adequate functionality. Thus, a medium pressure valve works from 67 up to $118 \mathrm{mmH} 2 \mathrm{O}$.

Hakin In-line ${ }^{\circledR}$ Precision Fixed Pressure Codman ${ }^{\circledR}$ medium pressure valve works at $70+/-10 \mathrm{mmH} 2 \mathrm{O}$ at $20 \mathrm{ml} / \mathrm{h}$; that is, it may go from 60 up to $80 \mathrm{mmH} 2 \mathrm{O}$.

Ventura ${ }^{\circledR}$ shunt valve has a medium pressure range also works at $70+/-10 \mathrm{mmH} 2 \mathrm{O}$ at $20 \mathrm{ml} / \mathrm{h}$; that is, it may go from 60 up to $80 \mathrm{mmH} 2 \mathrm{O}$. Thus, comparing all medium pressure valves, the lowest pressure allowed is $55 \mathrm{mmH} 2 \mathrm{O}$ and the highest pressure allowed is $140 \mathrm{mmH} 2 \mathrm{O}$, that is $8,5 \mathrm{~cm}$ of possible resistance variability among the diverse manufacturers.

Based on the data obtained of each presented valve, this study proposes a guideline to consult either a first-time shunt implantation or a shunt revision (Graphic 1).

\section{Discussion}

The management of hydrocephalus has challenged neurosurgeons, neurologists, engineers and medical device developers alike because of the unique nature of cerebrospinal fluid (CSF) dynamics in each patient.

Ideal shunt pressure-flow characteristics must match the patient's specific needs. However, postural (standing, sitting, or lying down) and vasogenic (blood flow) influences modify shunt function [10-12].

Most commercially available fixed DP shunts [13] are provided in three to five ranges: low, medium or high pressures (and very low and very high), depending on their response to the pressure differential between the shunt's upper and lower ends.

Opening pressure refers to a lying person, it varies considerably among individuals and it is classified while the individual is in the horizontal position. The disparity which will be mentioned among manufacturers has being identified previously by Tschan et al [14] who cites literally "There is a lack of general guidelines on the default pressure settings of shunt valves in both first time shunting to primarily avoid overdrainage and in shunt revision surgery to overcome manifest overdrainage". Allin [7] et al mentioned "ISO 7197 describes a set of standards that ensures a minimum assessment of a valve's performance and examines the consistency of the manufacturing process that is thought to be adequate". Perhaps surprisingly, not all shunt manufacturers adhere to these standards. As such, due to the varying and inconsistent data supplied by manufacturers concerning their product, it was considered important that formal studies, such as the one described here[8].

Shunt revisions with replacement of different brand manufacturers is a common neurosurgical procedure, notedly in developing countries where state health systems predominate and shunts are acquired by bidding. Additionally, more technologically developed shunts are not available for the majority of those countries, and this is applied to Brazil. The choice of a medium pressure shunt from a certain manufacturer by a high pressure shunt from another manufacturer is intuitive and the neurosurgeon thinks he is following a correct concept, but in many cases he may be led to equivocated choices.

The graphic 1 showed the shunt pressure range informed by manufacturing. We found a great variability between manufactures. It is easily identifiable that pressure ranges are different for each manufacturers. In Codman $₫$ and Ventura ${ }^{\circledR}$ shunts the pressure-flow characteristic informed was equal. Their shunts work basically at the same short opening pressure ranges, and they don't mix opening pressure ranges, that is, a medium pressure shunt never could be a normal pressure shunt. From Sophy ${ }^{\circledR}$, Medtronic ${ }^{\circledR}$ and Integra ${ }^{\circledR}$ also do not mix opening pressure ranges, but Medtronic ${ }^{\circledR}$ and Integra ${ }^{\circledR}$ have a much wider possible opening pressure range for each average pressure. Sophy ${ }^{\circledR}$ has three shunt pressure sets, low, medium or high, and it has a short pressure range for each one. They also have the highest median for each shunt pressure. A medium pressure shunt for Sophy ${ }^{\circledR}$ valve at corresponding flow to Codman $\AA$ and Ventura ${ }^{\circledR}$ is $125 \mathrm{mmH} 2 \mathrm{O}$, which basically is a high pressure valve for Codman and Ventura.

The Equivalency Graph (graphic 1) offers an easy comparative view of this phenomenon and others, demonstrating that all three shunts have basically the same operational range. In a hypothetical shunt revision with the intent to decrease the opening pressure due to image or clinical signs and/or symptoms of underdrainage despite an apparent correct positioning of the ventricular catheter, the replacement of a $\operatorname{Codman}{ }^{\circledR}$ or Ventura ${ }^{\circledR}$ High pressure shunt by a Sophy ${ }^{\circledR}$ Medium pressure shunt would be probably ineffective, because despite named differently, the operational range is the same. There is also a large "vacuum" of uncovered pressure ranges, but it is unknown if this peculiarity really matters, since that in the standing position all shunt resistances are overcome by gravity $[15,16]$. 
Graphic 1: Shunt Pressure Equivalency graphic table: Shunt manufacturers were given a different colour to be identified at the graphic, on the left side. Each small square represents $5 \mathrm{~mm} \mathrm{H} \mathrm{H}_{2} \mathrm{O}$. Each block represents a very-low pressure shunt, low pressure shunt, medium pressure shunt, and high-pressure shunt. Each column within the pressure block identifies the manufacturer by the colour. Pressure range for each shunt is represented by the vertical-coloured column for each pressure setting and shunt manufacturer. Pressure in $\mathrm{mmH}_{2} \mathrm{O}$ is identified on the right side.

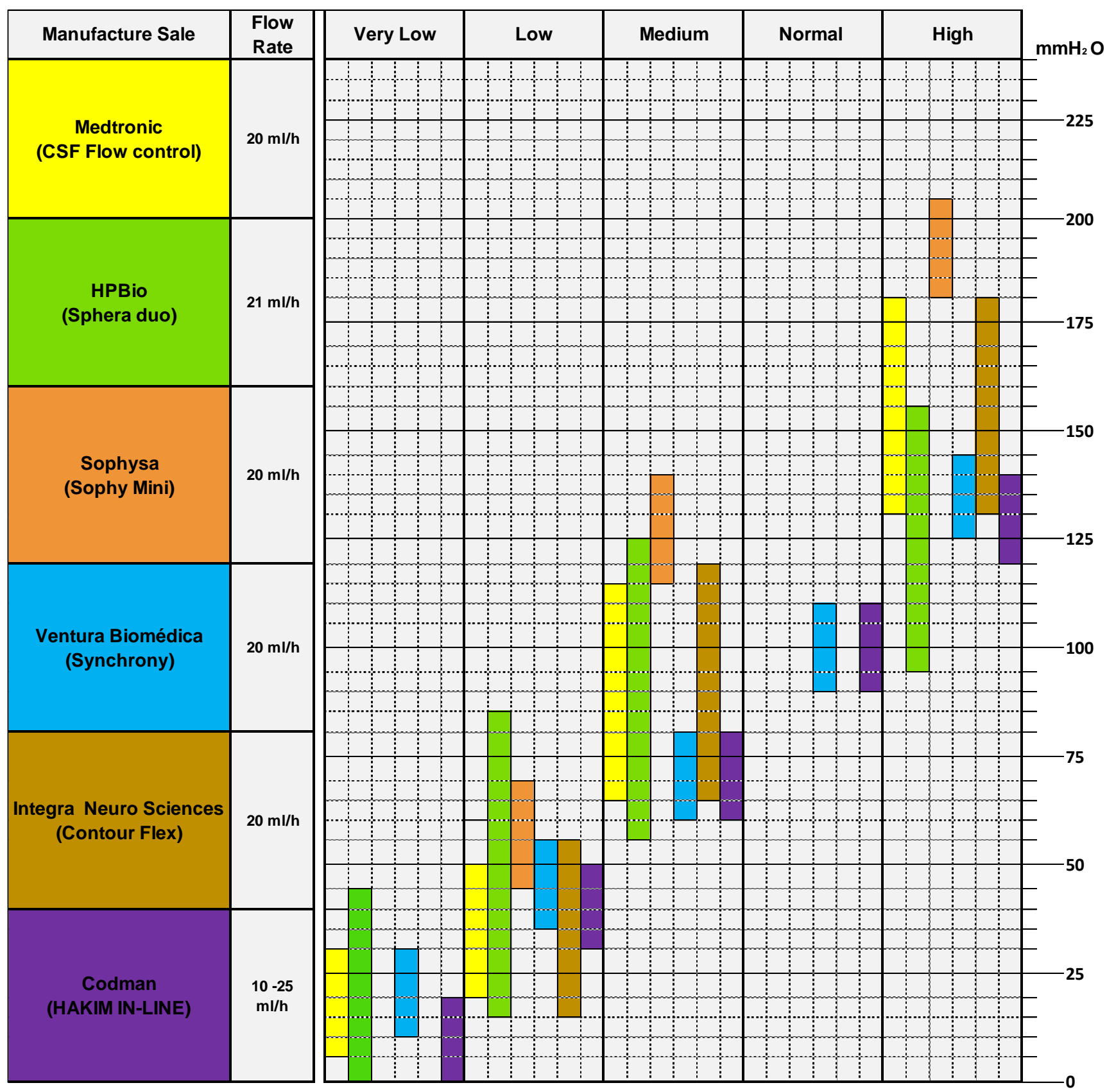

Yellow - Meditronic; HPbio - Green; Sophysa - Orange; Ventura - Blue; Integra - Ocre; Codman - Purple 
The drawback of a shunt with a high pressure range is related to shunt revisions. In another hypothetical situation, a certain patient may be hydrodynamically stabilized with an Integra medium pressure shunt which has an average median operational pressure at $90 \mathrm{mmH} 2 \mathrm{O}$, but for that shunt specifically the opening pressure is $110 \mathrm{mmH} 2 \mathrm{O}$, within the preconized pressure range specified by the manufacturer. It is required a shunt revision and a new Integra ${ }^{\circledR}$ medium pressure shunt is implanted. Due to the high pressure range, the patient may now have implanted a $70 \mathrm{mmH} 2 \mathrm{O}$ average medium pressure operational pressure shunt, and this difference may impact on the hydrodynamic performance of the patient. It is clearly evident by the graph that each manufacturer works with its own pressure settings. Once again, there is no right or wrong manufacturer or pressure settings among manufacturers. The flexibility of ISO 7197 allows the diversity of decisions and consider as a neurosurgeon's responsibility to be aware of the functionality of the product he works with.

The benefit of ISO 7197:2006 for the surgeon and the patient is to understand the information given by the manufacturer and to obtain standardized information about the performance of a well working product with new design characteristics. The benefit for the manufacturer is to define the important requirements for shunts as a basis for investigations during development as well as for quality control during manufacture", which means that there are four variables that are not regulated by ISO 7195. (1) The absolute pressure of a certain shunt (resistance). (2) The range for the absolute pressure (which would be the maximum accepted deviation from the absolute pressure). (3) The diameter and length specifications for the shunt. (4) The classification system for the pressure range. In another words, the shunt manufacturer is free to set up the operational range of the shunt, and as long as the shunt works as defined by the manufacturer, there is no problem at all, since there is no definition by ISO 7195. Thus, so many unspecified variables has a direct impact in a neurosurgeon's comprehension and affects his reasoning regarding the pressure set for the "first shunt " and the "next shunt".

As still there is a huge economic bridge to be overcome for four generation shunts to be available to the majority of the population. International neurosurgical societies should have a voice at ISO committee for the neurosurgeon's sake. An equivalent shunt pressure range isn't a difficult task for shunt manufacturers to follow. In the meantime, the author hopes that this equivalency table may be useful as a tool for those who face the problem of having to deal with different shunt brands.

Finally, the shunt assessment for medical use is also based on evaluation of the functioning of the bench test, within the context of its application and performed by each manufacturer who test their products for registration at ANVISA (Brazilian Health
Regulatory Agency) to guarantee the quality of the devices. ANVISA does not carry out the tests, but audits the manufacturers frequently to maintain the shunt registrations.

\section{Conclusion}

There is no standardization regarding the pressure which defines the different models of shunts available in Brazil and neurosurgeon must be aware when choosing a specific shunt and even more when, in a shunt review, choose another manufacturer. There is an overlapping regarding to shunt classification among shunts analysed and available in Brazil.

\section{Disclosure Statement}

Ângelo Maset is foundator and owner of Ventura ${ }^{\circledR}$ Biomedica Ltda. The other authors have no conflicts of interest

\section{Funding statement}

None.

\section{References}

1. Maset AL, Camilo Pinto JR, Andrade JR, Xavier VE. Consideraçōes hidrodinâmicas sobre a derivação liquórica. Parte IV: Tecnologia de válvulas - Primeira Geração. Arq Bras Neurocir 2009 Sep;28(3):87-96.

2. Camilo Pinto JR, Maset AL, Andrade JR, Mancini BM, Pereira GML, Barbosa RC, Rollo JMDA. Evaluation of flow rate accuracy and pressure measurements of testing rig for neurological valve hydrodynamic tests. Braz J Biom Eng 2014 Mar;30(1), 27-34.

3. International Organization for Standardization. ISO 7197. Neurological implants: sterile, single-use hydrocephalus shunts and components. Geneve, 2006. Revised 2016.

4. Rekate HL. Shunt-related headaches: the slit ventricle syndromes. Childs Nerv Syst. 2008 Apr;24(4):423-30

5. Ros B, Iglesias S, Martín Á, Carrasco A, Ibáñez G, Arráez MA. Shunt overdrainage syndrome: review of the literature. Neurosurg Rev. 2018 Oct;41(4):969-981.

6. Suriano IC. Interferência do comprimento e ou do diâmetro interno do cateter peritoneal no funcionamento do sistema de derivação ventrículoperitoneal. Tese apresentada à Universidade Federal de São Paulo - Escola Paulista de Medicina para obtenção do título de Doutor em Ciências. São Paulo 2017.

7. Allin DM, Czosnika ZH, Czosnika M, Richards HK, Pickard J: In vitro hydrodynamics properties of the 
Miethke prorGAV hydrocephalus shunt. Cerebrospinal Fluid Research 2006, 3:9.

8. Czosnika Z, Czosnika M, Richards HK, Pickard JD. Laboratory Testing of Hydrocephalus Shunts - Conclusion of the U.K. Shunt Evaluation Programme. Acta Neurochir 2002 144:525-538.

9. Maset AL, Suriano IC, Monteiro R, Camilo Pinto JR, Andrade JR, Mancini BM et al. Shunt implantations and peritoneal catheters: do no cut beyond $20 \mathrm{~cm}$. Surg Neurol Internat 2014,5:130.

10. Gebert AF, Schulz M, Habert H, Thomale UW. Adjustments in gravitational valves for the treatment of childhood hydrocephalus - a retrospective survey. Childs Nerv Syst 2013 Nov;29(11):2019-25.

11. Aschoff A, Kremer R, Benesch C, Fruh K, Klank A, Kunze S. Overdrainage and shunt technology. A critical comparison of programmable, hydrostatic and variable-resistance valves and flowreducing devices. Childs Nerv Syst 1995 11:193-202. 12. Browd S, Gottfried ON, Raggel BT, Kestle JRW. Failure of cerebrospinal fluid shunts: Part II: overdrainage, loculation, and abdominal complications. Pediatr Neurol 2006 34(3):171-176.
Furlanetti LL, Ballestero MFM, de Oliveira RS. Shunt Technology in Pediatric Neurosurgery: Current options and Scientific Evidence. Arch Pediat Neurosurg [Internet]. 2020Jun.18 [cited 2021Jan.26];2(2(May-August):e342020.

13. Tschan CA, Antes S, Huthman A, Vulcu S, Oertel J, Wagner W. Overcoming CSF drainage with the adjustable gravitational valve Prosa. Acta Neurochir (Wien) 2014 Apr;156(4):767-76.

14. Eymann R, Steudel WI, Kiefer M. Pediatric gravitational shunts: initial results from a prospective study. J Neurosurg 2007 (Suppl 3 Pediatrics) 106:179184.

15. Freimann FB, Sprung C. Shunting with gravitational valves - can adjustments end the era of revisions for overdrainage related events ? J Neurosurg 2012 117:1197-1204. 
